\title{
Inadvertent migration of guidewire into Murphy's eye of endotracheal tube during percutaneous dilatational tracheostomy
}

\author{
Binita Panigrahi, Devi Prasad Samaddar, Tushar Kumar
}

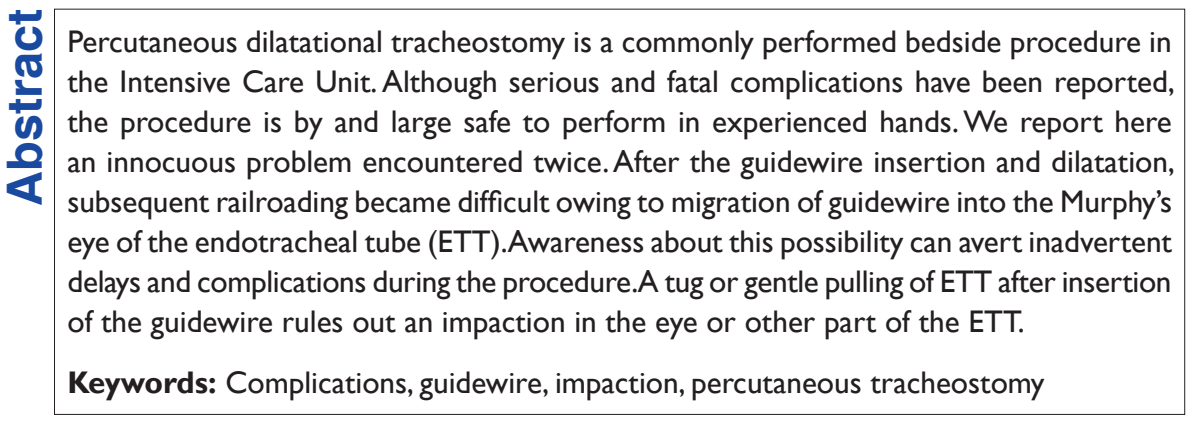

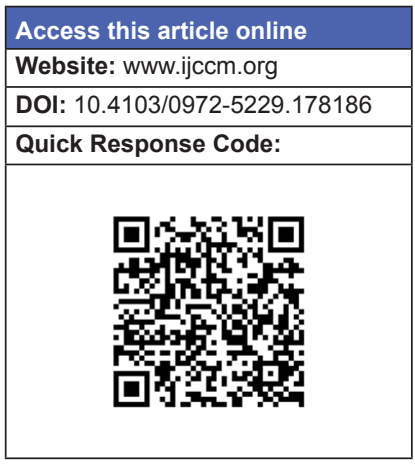

\section{Introduction}

Percutaneous dilatational tracheostomy (PDT) is one of the favored procedures for elective tracheostomy in Intensive Care Units. Complications happen when surrounding structures are traumatized. We report a case of percutaneous tracheostomy without assistance of a bronchoscope in which the J-tipped guidewire entered into the endotracheal tube (ETT) through the Murphy's eye and caused difficulty in railroading tracheostomy tube. A similar incident has been reported where the guidewire migrating into Murphy's eye did not allow dilatation. ${ }^{[1]} \mathrm{We}$ encountered a scenario wherein the guidewire migrating into the ETT allowed dilatation but did not allow subsequent railroading of the tracheostomy tube.

\section{Case Report}

A 22-year-old, mentally challenged young male operated for exploratory laparotomy, was scheduled

\section{From:}

Department of Anesthesiology and Critical Care, Tata Main Hospital,

Jamshedpur, Jharkhand, India

\section{Correspondence:}

Dr. Binita Panigrahi, Duplex No 10, Road No 6, Sangam

Vihar, P.O. Sonari, Jamshedpur - 831 011, Jharkhand, India.

E-mail: binitapanigrahi@ hotmail.com electively for percutaneous tracheostomy to facilitate weaning from positive pressure ventilation and sedation after failed trial of weaning.

Percutaneous tracheostomy was performed at the bedside under standard monitoring care. Informed consent was taken. Supplemental sedation and analgesia were given along with $100 \%$ oxygen through the ventilator. The patient was positioned supine with a pillow under the shoulders to extend the neck. The anatomical landmarks were identified and marked. A dose of $10 \mathrm{mg}$ of morphine with graded dose of intravenous propofol was administered. Direct laryngoscopy was performed, supraglottic suctioning was done, and the ETT was withdrawn to the laryngeal inlet after deflating the cuff partially.

This is an open access article distributed under the terms of the Creative Commons Attribution-NonCommercial-ShareAlike 3.0 License, which allows others to remix, tweak, and build upon the work non-commercially, as long as the author is credited and the new creations are licensed under the identical terms.

For reprints contact: reprints@ medknow.com

How to cite this article: Panigrahi B, Samaddar DP, Kumar T. Inadvertent migration of guidewire into Murphy's eye of endotracheal tube during percutaneous dilatational tracheostomy. Indian J Crit Care Med 2016;20:188-90. 
The skin was prepared and sterile draping was done. About $4 \mathrm{ml}$ of $2 \%$ lidocaine was used for local infiltration. A transverse incision of $1 \mathrm{~cm}$ was made midway between suprasternal notch and thyroid prominence. Blunt dissection was done to separate the paratracheal muscles and expose the pretracheal fascia. A 16-gauge needle and cannula attached with a syringe were inserted in a caudal direction between the second and third tracheal ring. The placement of the needle was confirmed by free aspiration of air. The cannula was left in place and the needle with syringe withdrawn. Free air was aspirated again to reconfirm the placement of cannula into the tracheal lumen. A flexible J-tipped guidewire was inserted through the cannula and the latter was removed. Three metal dilators of increasing caliber were serially passed over the guidewire through the soft tissues of the neck into the trachea. The tract was then dilated with the Howard-Kelly forceps. The tracheostomy tube with obturator was threaded over the guidewire into the trachea. However, the tube failed to enter into trachea. The obturator and tracheostomy tube were removed from the guidewire assuming that the tracheal stoma was under-dilated. The tract was then again dilated with the help of Howard-Kelly forceps, and we failed to railroad the tracheostomy tube over the guidewire again. The procedure was stopped for a moment assuming that ETT was interfering. The ETT was in its proper place, i.e., the cuff still situated at the vocal cords level. However, it was withdrawn a little bit more. This maneuver dragged the guidewire cephalad. It was then realized that the guidewire had entered into the lumen of ETT thus moved in retrograde fashion through the Murphy's eye. As the ETT was removed, the guidewire came along with it [Figure 1]. Direct laryngoscopy was done and the patient was reintubated. Because the stoma was well formed, guidewire was again passed by Seldinger's technique

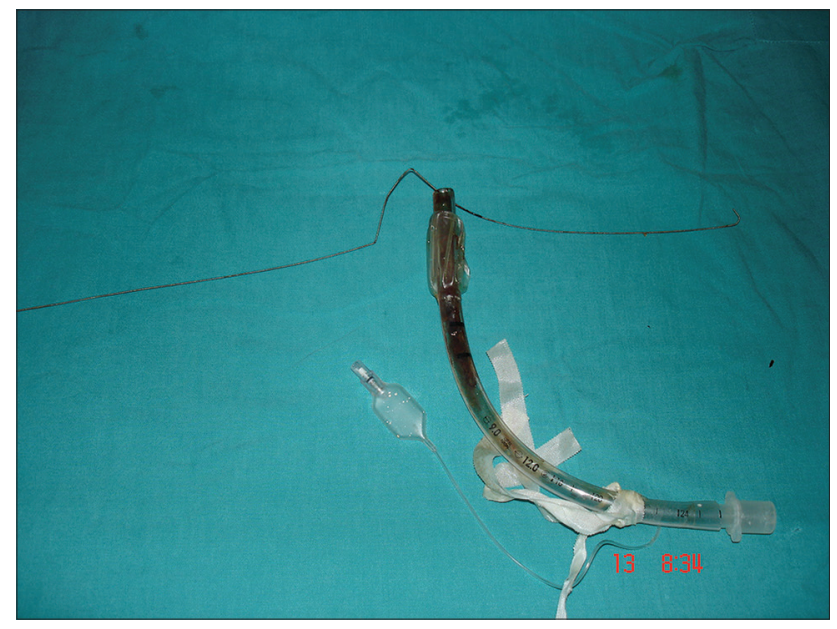

Figure I: Guidewire-impacted in endotracheal tube in the first case followed by passing the tracheostomy tube with the obturator without any difficulty. Placement of the tracheostomy tube was confirmed by manual ventilation and auscultation. Posttracheostomy chest $X$-ray showed its normal location without any complication. The patient was successfully weaned off the ventilator and sedation after $48 \mathrm{~h}$.

We went through the register of the unit to realize that similar reporting had been done 7 years back. On contacting the operator, a picture of the ETT with the wire was obtained from archive [Figure 2]; however, the case details could not be procured.

\section{Discussion}

Toy and Weinstein first described percutaneous tracheostomy in 1969. ${ }^{[2]}$ PDT is a frequently carried out procedure in a critical care setting. It is performed in majority of patients by a intensivist as a bedside procedure, under endoscopic guidance. Simple PDT is not devoid of complications, especially if done without endoscopic guidance; operator skill is vital. ${ }^{[3]}$ In the largest case series published, complication rates have been as low as $1.4 \%$ in PDT, which makes it safe and the preferred technique. ${ }^{[4]}$ Documented common complications have been mostly malposition, bleeding, and infection and fatal complications have been hemorrhage. ${ }^{[4,5]}$ Tension pneumothorax during the procedure has also been reported. ${ }^{[6]}$ Another series of two hundred cases has reported only one event of knotted guidewire. ${ }^{[7]}$ In our case, the introducer needle pierced the Murphy's eye, causing the guidewire to get entangled. The fact that the complication is immediately detected and corrected without any damage done might be the reason for under-reporting. Many devices have been reported to have migrated into the Murphy's eye

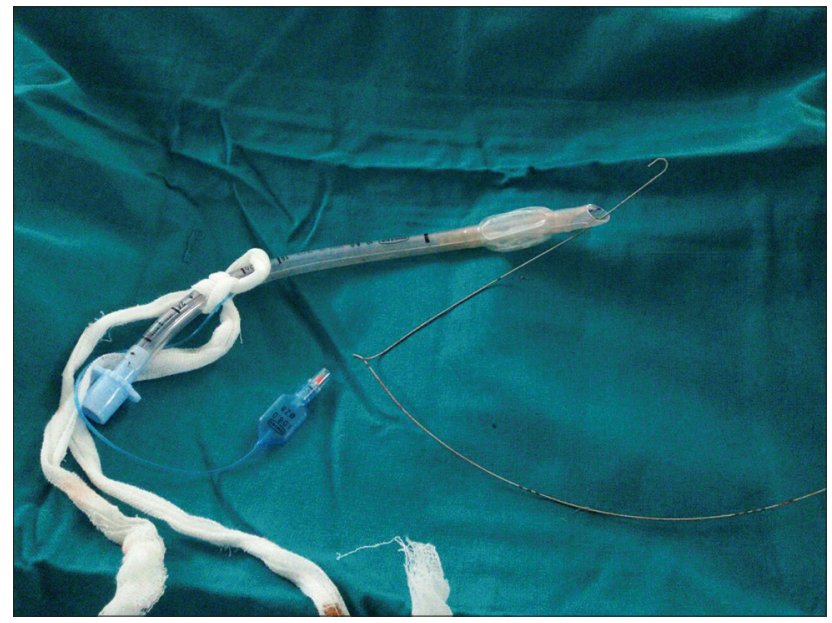

Figure 2: Guidewire-inside endotracheal tube in the second case 
such as fiberoptic bronchoscope, tube changers, curved tip catheters, and one arm of forceps causing difficulties with procedures ${ }^{[8]}$ These complications may be averted with the use of endoscopic guidance. ${ }^{[9,10]}$

Fiberoptic bronchoscope guidance is recommended in cases of difficult anatomy or where placement is doubtful. However, this method runs the risk of hypercarbia and raised intracranial pressure and has been shown to have comparable results as compared to blind method. ${ }^{[11]}$ Modified Ciaglia technique precludes its use as the tracheal fascia is directly visualized. Ultrasound guidance is another approach to identify tracheal midline, level of tracheal cartilage, and identification of adjacent blood vessel and thyroid gland; however, it does not guarantee midline puncture or detection of a misplaced guidewire. ${ }^{[12]}$ The use of these diagnostic modalities is recommended as an adjunct in select cases where problems are anticipated.

\section{Financial support and sponsorship} Nil.

\section{Conflicts of interest}

There are no conflicts of interest.

\section{References}

1. Hill SA. An unusual complication of percutaneous tracheostomy. Anaesthesia 1995;50:469-70.

2. Toy FJ, Weinstein JD. A percutaneous tracheostomy device. Surgery 1969;65:384-9

3. Kornblith LZ, Burlew CC, Moore EE, Haenel JB, Kashuk JL, Biffl WL, et al. One thousand bedside percutaneous tracheostomies in the surgical intensive care unit: Time to change the gold standard. J Am Coll Surg 2011;212:163-70.

4. Ferraro F, Marullo L, d'Elia A, Izzo G. Elective tracheostomy in intensive care unit: Looking between techniques, a three cases report. Indian J Anaesth 2014;58:190-2.

5. McCormick B, Manara AR. Mortality from percutaneous dilatational tracheostomy. A report of three cases. Anaesthesia 2005;60:490-5.

6. Arunkumar AS, Vydhyanadhan T, Ravikumar A, Kamat V. An unusual complication of percutaneous dilatational tracheostomy. Indian J Crit Care Med 2004;8:40-2.

7. Siranovic M, Gopcevic S, Kelecic M, Kovac N, Kriksik V, Rode B, et al. Early complications of percutaneous tracheostomy using the Grigg: method. Signa Vitae 2007;2:18-20.

8. Barba CA, Angood PB, Kauder DR, Latenser B, Martin K, McGonigal MD, et al. Bronchoscopic guidance makes percutaneous tracheostomy a safe, cost-effective, and easy-to-teach procedure. Surgery 1995;118:879-83.

9. Powell DM, Price PD, Forrest LA. Review of percutaneous tracheostomy. Laryngoscope 1998;108:170-7.

10. Vargas M, Sutherasan Y, Antonelli M, Brunetti I, Corcione A, Laffey JG, et al. Tracheostomy procedures in the intensive care unit: An international survey. Crit Care 2015;19:291.

11. Bouvette M, Fuhrman TM. Preventing complications during percutaneous tracheostomy. Anesthesiology 1999;90:918-9.

12. Kleine-Brueggeney M, Greif R, Ross S, Eichenberger U, Moriggl B, Arnold A, et al. Ultrasound-guided percutaneous tracheal puncture A computer-tomographic controlled study in cadavers. Br J Anaesth 2011;106:738-42. 